\title{
МЕТОДИЧЕСКИЕ АСПЕКТЫ АНАЛИЗА РЕЗУЛЬТАТИВНОСТИ МАРКЕТИНГОВОЙ ДЕЯЛЬНОСТИ ПРЕДПРИЯТИЙ ПЕРЕРАБАТЫЫВАЮЩЕЙ ПРОМЫШЛЕННОСТИ В СФЕРЕ ВНЕШНЕЙ ТОРГОВЛИ
}

\author{
METHODOLOGICAL ASPECTS OF THE MARKETING \\ ACTIVITIES PERFORMANCE ANALYSIS \\ OF THE PROCESSING INDUSTRY ENTERPRISES \\ IN THE SPHERE OF FOREIGN TRADE
}

\author{
Пармакли Дмитрий Михайлович \\ доктор хабилитат экономических наук, профрессор, \\ Комратский государственный университет Республики Молдова \\ ORCID: https://orcid.org/0000-0003-2002-6104 \\ Запша Галина Николаевна \\ доктор экономических наук, профессор, \\ Одесский государственный аграрный университет \\ ORCID: https://orcid.org/0000-0003-2657-9367 \\ Бахчиванжи Людмила Анатольевна \\ кандидат экономических наук, доцент, \\ Одесская национальная академия пищевых технологий \\ ORCID: https://orcid.org/0000-0001-8381-9684 \\ Parmacli Dmitrii \\ Comrat State University, Republic of Moldova \\ Zapsha Galina \\ Odessa State Agrarian University \\ Bakhchyvanzhy Liudmila \\ Odessa National Academy of Food Technologies
}

Проанализирована динамика основных фринансово-экономических показателей маркетинговой деятельности перерабатывающих предприятий агропромышленного комплекса, фрункционирующих в сфере внешней торговли. Подчеркнута необходимость использования особого подхода при анализе динамики показателей предприятий, для которых характерна низкая устойчивость производства. В связи с этим предлагается проводить расчеты среднегодовых скользящих показателей, которые позволят сглаживать экстремальные значения. Маркетинговый анализ динамики фринансово-экономических показателей рассмотрены на примере предприятий Республики Молдова и Одесской Области Украины по данным их деятельности за 2014-2020 годы. Освещена методика анализа показателей в динамике. Широко использован графический метод исследования в маркетинговом анализе, который позволил выявить среднегодовые значения темпов роста показателей на основе уравнений трендов и ссрормировать банк моделей как составляющих элементов маркетинговой инорормационной системы.

Ключевые слова: маркетинговый анализ, маркетинговые модели динамики, доходы от продаж, валовая прибыль, чистая прибыль, коэффициент вариации, стабильность.

Мета дослідження полягала в обґрунтуванні методичних аспектів аналізу основних фрінансово-економічних показників, що характеризують результативність маркетингової діяльності переробних підприємств агропромислового комплексу у сорері зовнішньої торгівлі в динаміці. Наголошено на необхідності використання особливого підходу при аналізі динаміки показників підприємств, для яких характерна низька стійкість ви- 
робництва. Пропонується проводити розрахунки середньорічних ковзних показників динаміки, що дозволять згладжувати екстремальні значення. Аналіз динаміки фінансово-економічних показників маркетингової діяльності розглянуто на прикладі підприємств Республіки Молдова та Одеської області, що функціонують у сфрері агропромислового комплексу та постачають на експорт продукцію зернових, олійних культур та харчову продукцію власного виробництва. Динаміка показників аналізується за 2014-2020 роки, що дозволило виявити закономірності змін та оцінити рівень стійкості виробництва і реалізації продукції як індикаторів результативності та ефективності маркетингової діяльності. Висвітлено методику аналізу показників у динаміці. В аналізі динаміки фрінансово-економічних результатів маркетингової діяльності важливо виявити їх стабільність, для чого розраховано значення показників в середньому за рік, середньорічні відхилення, коефріцієнт варіації і розмах варіації. Особливість методики аналізу полягала у використанні поряд з річними ковзними параметрами аналізованих показників трирічних ковзних їх кількісного значення, що дозволило констатувати інтенсивне зростання варіації, зокрема показників прибутку. Широко використаний графрічний метод дослідження динаміки показників, виявлено середньорічні значення темпів зростання на основі рівнянь трендів Практична цінність отриманих результатів полягає в тому, що дослідження дозволило ссормувати банк трендових моделей показників доходу від реалізації, собівартості продажу продукції, валового прибутку та прибутку до оподаткування, чистого прибутку як складових елементів маркетингової інформаційної системи досліджуваних підприємств.

Ключові слова: маркетинговий аналіз, маркетингові моделі динаміки, доходи від продаж, валовий прибуток, чистий прибуток, коефіцієнт варіації, стабільність.

The purpose of the study was to substantiate the methodological aspects of the analysis of the main financial and economic indicators that characterize the effectiveness of marketing activities of processing enterprises of the agro-industrial complex in the field of foreign trade in dynamics. There is need to use a special approach in the analysis of the enterprises indicators dynamics, which are characterized by low stability of production. It is offered to carry out calculations of average annual sliding indicators of dynamics that will allow smoothing out extreme values. The analysis of the dynamics of financial and economic indicators of marketing activities is considered on the example of enterprises of the Republic of Moldova and Odessa region, operating in the field of agro-industrial complex and supplying for export grain, oilseeds and food products of own production. The dynamics of indicators is analyzed for 2014-2020, which allowed identifying patterns of change and assessing the level of sustainability of production and sales as indicators of effectiveness and efficiency of marketing activities. The method of analysis of indicators in dynamics is covered. In the analysis of the dynamics of financial and economic results of marketing activities, it is important to identify their stability, for which the values of indicators are calculated on average per year, average annual deviations, and coefficient of variation and scope of variation. The peculiarity of the analysis method was the use along with the annual sliding parameters of the analyzed indicators of three-year sliding their quantitative value, which allowed stating the intensive growth of variation, in particular profit indicators. Widely used graphical method of studying the dynamics of indicators, the average annual growth rates based on trend equations The practical value of the results is that the study allowed to form a bank of trend models of sales revenue, cost of sales, gross profit and pre-tax profit, net profit as components of the marketing information system of the studied enterprises.

Keywords: marketing analysis, marketing dynamics models, sales revenues, gross profit, net profit, coefficient of variation, stability.

Постановка проблемы. В условиях рыночной экономики для предприятий агропромышленного комплекса, которые выходят на внешние рынки продукции переработки зерновых и масличных культур, важно обеспечить эфрфективное и результативное осуществление маркетинговой деятельности. Это в свою очередь требует совершенствования методического обеспечения анализа основных индикаторов результативности маркетинга. К основным фринансово-экономическим индикаторам результативности маркетинговой деятельности предприятий относятся: доходы от продаж (продукции, товаров услуг), валовая прибыль (прибыль от реализации продукции), прибыль до налогообложения и чистая прибыль. Выполнение анализа основных показателей результативности маркетинговой деятельности имеет большое значение для перерабатывающих предприятий, использующих в своей деятельности продукцию сельского хозяйства, отличающихся неустойчивым характером производства, вызванного преимущественно непредсказуемыми погодно-климатическими условиями. В связи с этим проблема методического обеспечения маркетингового анализа агропромышленных предприятий, фрункционирующих в сорере внешней торговли, является вполне актуальной как для молдавских, так и украинских предприятий и, прежде всего, расположенных в зонах неустойчивого земледелия Республики Молдова и Одесской области.

Анализ последних исследований и публикаций. В научной литературе достаточно большое внимание уделяется в последние годы проблемам маркетингового управления и анализу комплекса маркетинга, достаточно широко обоснованы направления использования матричных методов анализа 
внешней маркетинговой среды, маркетинговой товарной и ценовой политики, анализа маркетинговых коммуникаций. Вопросы маркетингового анализа и набора его инструментария обобщаются в публикации Гайдуковича Д.С. [1]. Коллективом авторов в публикации под редакцией Д.А. Штефанича дается сравнительная характеристика инструментов маркетингового и стратегического анализа [2]. Основные объекты маркетингового анализа комплекса маркетинга и маркетинговый анализ как инструмент удовлетворения инорормационных потребностей рыночно ориентированного предприятия характеризует Дейнега О.В. [3]. Рассматривая методические положения комплексного маркетингового анализа, Морохова В.О., Бойко В.О., Борзаковская Л.В. обосновывают направления и показатели анализа, отмечая, что для анализа экспортно-импортной ориентации рынка необходимо использовать экономико-статистические методы, фракторный анализ, показатели объема производства и реализации [4, с. 196].

С позиций системного похода рассматривает маркетинговый анализ Л.О. Стрий, обращая внимание на методические подходы с использованием экономико-математического моделирования. Автор предлагает оценивать эфрфективность маркетинга предприятия или через систему показателей результативности фрункционирования подсистем маркетинга в структуре управления предприятием, или через оценку эсрсрективности рыночного распределения позиции предприятия и уровня экономической эффрективности его деятельности в сфере производства и реализации продукции [5].

Актуальность проблемы маркетингового анализа в предприятиях агропромышленного комплекса подчеркивается в публикации Т.В. Штучки. Автор отмечает, что агропродовольственный сектор имеет настолько глубокую специфрику, что ее игнорирование при использовании современных методик оценки эфроективности маркетинговой деятельности приводит к искривлению их результатов [6, с. 96].

Выделение нерешенных ранее частей общей проблемы. Несмотря на широкое освещение в научной литературе методики и методов маркетингового анализа, недостаточно публикаций посвящено особенностям анализа в разрезе видов экономической деятельности. В частности, недостаточное методическое обоснование характеризует освещение анализа результативности маркетинговой деятельности перерабатывающих предприятий агропромышленного комплекса, особенно методов анализа устойчивости результатов деятельности с использованием графрического метода и количественных индикаторов фринансово-экономических результатов маркетинговой деятельности, в то время как методика матричных и экспертных методов разработана гораздо глубже. Особенно актуальными эти вопросы являются в силу того, что предприятия, срункционирующие в ссрере внешней торговли с выходом на внешние аграрные рынки, вследствие особенностей отрасли и зависимости результатов деятельности от погодных условий и изменений климата, в отдельные годы несут значительные потери и характеризуются высокой нестабильностью окупаемости затрат на маркетинг валовой прибылью от реализации на национальном рынке и экспортных поставок продукции. Вопросы анализа результативных показателей маркетинговой деятельности с учетом высокой их нестабильности и с использованием особого подхода к изучению динамики на основе скользящих средних величин и грасрического метода в научных публикациях отражены недостаточно.

Формулирование целей статьи (постановка задач). Цель исследования - обосновать некоторые особенности анализа показателей результативности маркетинговой деятельности предприятий, перерабатывающих продукцию агропредприятий и поставляющих ее на экспорт в рамках внешней торговли. Характерной чертой деятельности этих предприятий является нестабильный характер как объема производства, так цен реализации сельскохозяйственной продукции.

Изложение основного материала исследования. Высокая нестабильность годовых показателей производства характерна для сельскохозяйственных предприятий Республики Молдова и Одесской области, расположенных в зоне рискованного (неустойчивого) земледелия. Зачастую неблагоприятные погодные условия не только влияют на качество продукции, но и не дают возможности произвести запланированный объем продукции, и, как следствие, получить необходимую прибыль. Сложные погодные условия, такие, как жара и продолжительные периоды отсутствия осадков, часто приводят к потерям урожая сельскохозяйственных культур. В результате чего могут полностью погибнуть посевы гороха, кукурузы на зерно, озимых и других культур или урожайность этих культур может быть снижена настолько, когда использование продукции по назначению: 
для переработки или экспорта на внешние рынки, - становится низкорентабельным или даже убыточным. Специалисты, оценивая современную тенденцию изменения климата, приходят к выводу о наступающем потеплении. Проблемы опустынивания в таких условиях кажутся ныне не праздными [7, с. 194].

В силу вышеизложенного, перерабатывающие предприятия характеризуются низкой устойчивостью основных показателей результативности маркетинговой деятельности. Существенно разнятся годовые показатели переработанной (использованной) продукции, что, разумеется, непосредственно сказывается на объемах, как операционной, так и чистой прибыли. В связи с этим актуальными являются поиски новых подходов по совершенствованию методик оценки деятельности предприятий в динамике, позволяющих выявить характер тенденции, «скорости» роста или падения, устойчивости или стабильности показателей и других характеристик исследуемых субъектов хозяйствования [8, с. 82].

Некоторые особенности анализа основных показателей деятельности перерабатывающих предприятий рассмотрим на примере акционерного общества (AO) «Cahulpan» Кагульского района Республики Молдова и общества с ограниченной ответственностью (ООО) «ПП Теклайн», расположенного в городе Одесса и поставляющего на экспорт сельскохозяйственную продукцию, продукцию переработки зерновых, зернобобовых, крупяных и масличных культур. Сложившиеся основные показатели деятельности предприятий за последние 7 лет (2014-2020 годы) представлены соответственно в таблицах 1 и 2.

Выясним изменения показателей за исследуемые 7 лет, для чего сравним показатели 2020 года с 2014 годом. Абсолютные изменения находим по фрормуле (1):

$$
\Delta B \Pi=\frac{\mathrm{B} \Pi_{\mathrm{n}}-\mathrm{B} \Pi_{1}}{\mathrm{n}-1}
$$

где $\mathrm{B}_{\mathrm{n}}$ и ВП ${ }_{1}-$ соответственно показатели последнего и первого года периода исследования;

$\mathrm{n}$ - число лет исследуемого периода.

С 2014 по 2020 годы изменения составили:

- по доходам от продаж:

для $A O$ «Cahulpan»

$$
\Delta \mathrm{BП}=\frac{45029-53515}{6}=-1414,3 \text { тыс. лей; }
$$

для ООО «ПП Теклайн»

$$
\Delta \mathrm{B} \Pi=\frac{36049-16384}{6}=3277,5 \text { тыс. грн.; }
$$

Основные исходные показатели деятельности АO «Cahulpan»

Таблица 1 за 2014-2020 годы (тыс. лей)

\begin{tabular}{|c|c|c|c|c|c|}
\hline Год & $\begin{array}{c}\text { Доход от } \\
\text { реализации }\end{array}$ & Себестоимость & $\begin{array}{c}\text { Валовая } \\
\text { прибыль }\end{array}$ & $\begin{array}{c}\text { Прибыль до } \\
\text { налогообложения }\end{array}$ & $\begin{array}{c}\text { Чистая } \\
\text { прибыль }\end{array}$ \\
\hline 2014 & 53515 & 39402 & 14113 & 1746 & 1414 \\
\hline 2015 & 55052 & 40838 & 14214 & 1146 & 824 \\
\hline 2016 & 52639 & 39380 & 13249 & 619 & 383 \\
\hline 2017 & 50742 & 38573 & 12169 & 1169 & 862 \\
\hline 2018 & 48072 & 35773 & 12299 & 1979 & 1693 \\
\hline 2019 & 47621 & 36168 & 11453 & 1221 & 1012 \\
\hline 2020 & 45029 & 34617 & 10412 & 470 & 398 \\
\hline
\end{tabular}

Источник: данные бухгалтерского учета предприятия

Таблица 2

\begin{tabular}{|c|c|c|c|c|c|c|c|}
\hline \multirow{2}{*}{ Показатели } & \multicolumn{7}{|c|}{ Годы } \\
\hline & 2014 & 2015 & 2016 & 2017 & 2018 & 2019 & 2020 \\
\hline Доходы от продаж & 16384 & 18346 & 16011 & 15961 & 15405 & 16790 & 36049 \\
\hline Себестоимость продаж & 10843 & 12864 & 11050 & 11182 & 12254 & 14509 & 33878 \\
\hline Валовая прибыль & 5541 & 5482 & 4961 & 4780 & 3151 & 2282 & 2171 \\
\hline Прибыль до налогообложения & 2549 & 3015 & 2045 & 1976 & 1010 & 370 & 1388 \\
\hline Чистая прибыль & 2202 & 2605 & 1767 & 1707 & 829 & 303 & 1138 \\
\hline
\end{tabular}

Основные исходные показатели деятельности ООО «ПП Теклайн» за 2014-2020 годы (тыс. грн)

Источник: данные фринансового учета предприятия 
- по валовой прибыли:

для $\mathrm{AO}$ «Cahulpan»

$$
\Delta \mathrm{B} \Pi=\frac{10412-14113}{6}=-616,8 \text { тыс. лей; }
$$

для ООО «ПП Теклайн»

$$
\Delta \mathrm{B} \Pi=\frac{2121-5541}{6}=-570,0 \text { тыс. грн.; }
$$

- по чистой прибыли:

для $\mathrm{AO}$ «Cahulpan»

$$
\Delta \mathrm{B} \Pi=\frac{398-1414}{6}=-169,3 \text { тыс. лей; }
$$

для ООО «ПП Теклайн»

$$
\Delta \mathrm{B} \Pi=\frac{1138-2202}{6}=-177,3 \text { тыс. грн.; }
$$

Относительный показатель роста (или снижения) определяют по фрормуле (2):

$$
\Delta \mathrm{B} \Pi=\sqrt[n-1]{\frac{B \Pi_{n}}{B \Pi_{1}}}
$$

За исследуемые годы изменения составили:

- доходов от продаж:

для $A O$ «Cahulpan»

$$
\Delta \mathrm{B} \Pi=\sqrt[6]{\frac{45029}{53515}}=0,972 \text { или }-2,8 \% \text {; }
$$

для ООО «ПП Теклайн»

$$
\Delta \mathrm{B} \Pi=\sqrt[6]{\frac{36049}{16384}}=1,140 \text { или } 14,0 \% \text {; }
$$

- валовой прибыли:

для $A O$ «Cahulpan»

$$
\Delta \mathrm{B} \Pi=\sqrt[6]{\frac{10412}{14113}}=0,951 \text { или }-4,9 \% ;
$$

для ООО «ПП Теклайн»

$$
\Delta \mathrm{B} \Pi=\sqrt[6]{\frac{2121}{5541}}=0,852 \text { или }-14,8 \% ;
$$

- чистой прибыли

для $A O$ «Cahulpan»

$$
\Delta \mathrm{B} \Pi=\sqrt[6]{\frac{398}{1414}}=0,810 \text { или }-19,0 \% \text {; }
$$

для ООО «ПП Теклайн»

$$
\Delta \mathrm{B} \Pi=\sqrt[6]{\frac{1138}{2202}}=0,900 \text { или }-10,0 \% .
$$

Чтобы оценить среднегодовые темпы изменения показателей, построим графики динамики доходов от реализации продукции (рис. 1), чистой прибыли (рис. 2) и других показателей. Показав уравнения трендов изменения значений сринансово-экономических показателей, выявим величину их изменений в среднем за 7 лет. Полученные результаты представлены в таблице 3.

Например, в соответствии с уравнением тренда, представленном на рисунке 1
$(Y=1974 x+11381)$, в среднем за год доходы от продаж в ООО «ПП Теклайн» увеличивались на 1974 тыс. грн., а в AO «Cahulhan» уменьшались каждый год на сумму 1603 тыс. лей $(\mathrm{Y}=-1603 x+56794)$.

Данные таблицы 3 показывают, что тенденция роста показателей за годы исследований наблюдалась лишь при анализе динамики доходов от продаж и себестоимости продаж в ООО «ПП Теклайн». Все остальные анализируемые показатели развивались по нисходящей тенденции, то есть, уменьшаясь из года в год.

Изучая динамику фринансово-экономических показателей деятельности предприятий в динамике важно выявить их стабильность, для чего рассчитывают значения показателей в среднем за год, среднегодовые отклонения, коэсфрициент вариации и размах вариации. Данные значения легко определим с помощью компьютера. Напомним, что коэфффициент вариации определяем как отношение среднегодовых отклонений к среднегодовому значению показателя. Полученные результаты заносим в таблицу 4.

Если в результате расчетов коэфффициент вариации превышает $20 \%$, то анализируемый показатель характеризуется низкой устойчивостью. В нашем случае особенно заметна нестабильность показателей ООО «ПП Теклайн»: коэфрфициенты вариации себестоимости продаж и валовой прибыли превысили 50 \%. Для AO «Cahulhan» характерна высокая нестабильность лишь при формировании прибыли до налогообложения и чистой прибыли.

При анализе фринансово-экономических показателей более чем за 5 лет желательно период исследования разделить на две части. В нашем примере сравним значения показателей за первые и последние 3 года, т.е. за 2014-2016 и 2017-2020 годы (таблица 5). Во втором периоде, т.е за 2018-2020 годы несколько возросла нестабильность показателей в AO «Cahulhan». Наиболее заметен рост нестабильность прибыли до налогообложения на данном предприятии. Если в первом периоде коэфрфициент вариации составил 48,2\%, то во втором периоде он возрос до 61,7 \% или почти в 1,3 раза.

В ООО «ПП Теклайн» во втором периоде наблюдается значительный рост нестабильности анализируемых показателей. Так, коэффрициент вариации доходов от продаж возрос почти в 6,9 раза, себестоимости продаж почти в 5,7 раза, валовой прибыли - более чем в 3,5 раза, прибыли до налогообложения и чистой прибыли соответственно - более чем в 6,4 раза и 2,9 раза. 


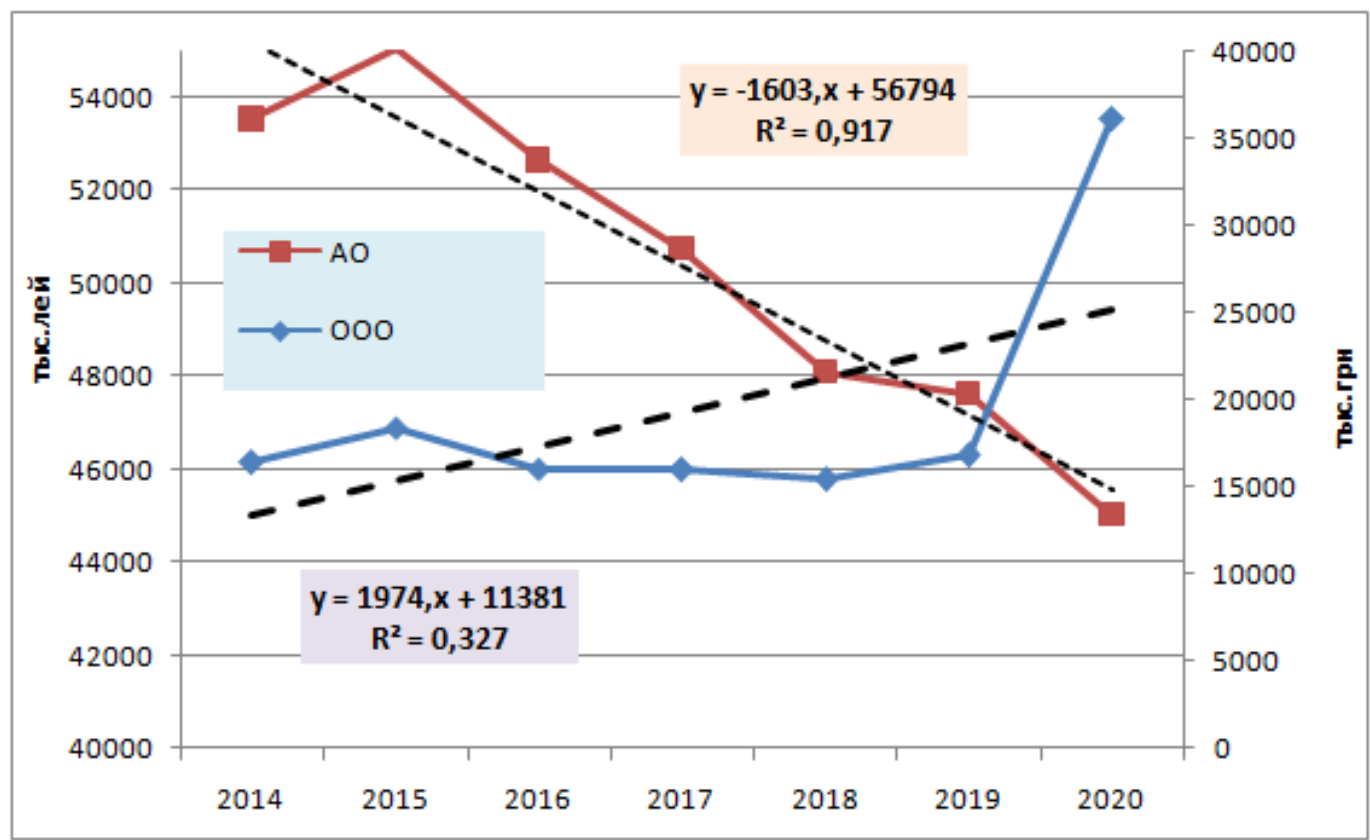

Рис. 1. Динамика доходов от продаж в АО «Cahulhan» и ООО «ПП Теклайн» за 2014-2020 годы

Источник: выполнено по данным таблиц 1 и 2

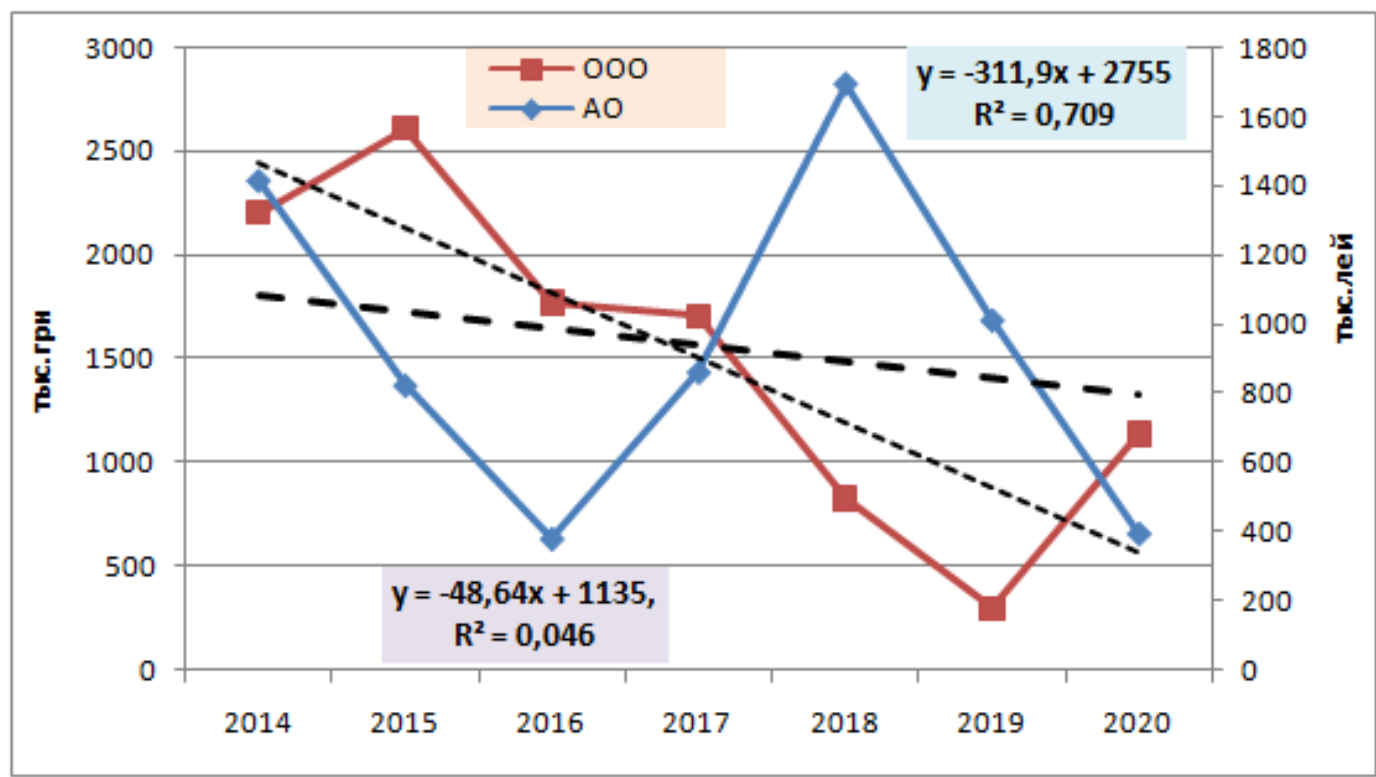

Рис. 2. Динамика чистой прибыли в AO «Cahulhan» и ООО «ПП Теклайн» за 2014-2020 годы

Источник: выполнено по данным таблиц 1 и 2

Важно в анализе использовать метод среднегодовой скользящей, заключающийся в том, что помимо годовых фринансово-экононые последние 3-5 лет. Расчет трехлетних скользящих показателей чистой прибыли в $\mathrm{AO}$ «Cahulhan» и ООО «Теклайн» представлены в таблице 6, а также на графриках (рис. 3 и 4).
Из графиков видно, что при использовании метода среднегодовой скользящей показатели чистой прибыли представлены относительно стабильными значениями, о чем свидетельствует коэфрсициент аппроксимации. При использовании среднегодовых значений этот коэфрфициент возрос в АО «Cahulhan» с 0,046 до 0,485 или почти в 11 раз, В 
Таблица 3

Расчеты среднегодовых темпов прироста (снижения) показателей AO «Cahulhan» (AO) и ООО «ПП Теклайн» (ООО) за 2014-2020 годы

\begin{tabular}{|l|c|l|c|}
\hline Наименование показателей & предприятие & Уравнение тренда & $\begin{array}{c}\text { Среднегодовой } \\
\text { прирост (снижение) }\end{array}$ \\
\hline \multirow{2}{*}{ Доход от продаж } & $\mathrm{AO}$ & $\mathrm{Y}=-1603 x+56794$ & -1603 тыс. лей \\
\hline \multirow{2}{*}{ Себестоимость продаж } & $\mathrm{OOO}$ & $\mathrm{Y}=1974 x+11381$ & 1974 тыс. грн. \\
\hline \multirow{2}{*}{ Валовая прибыль } & $\mathrm{AO}$ & $\mathrm{Y}=-975 x+41722$ & -975 тыс. лей \\
\cline { 2 - 4 } & $\mathrm{OOO}$ & $\mathrm{Y}=2628 x+4711$ & 2628 тыс. грн. \\
\hline \multirow{2}{*}{ Прибыль до налогообложения } & $\mathrm{AO}$ & $\mathrm{Y}=-627,6 x+15069$ & $-627,6$ тыс. лей \\
\cline { 2 - 4 } & $\mathrm{OOO}$ & $\mathrm{Y}=-654,2 x+6669$ & $-654,2$ тыс. грн. \\
\cline { 2 - 4 } & $\mathrm{AO}$ & $\mathrm{Y}=-82,78 x+1524$ & $-82,78$ тыс. лей \\
\hline \multirow{2}{*}{ Оистая прибыль } & $\mathrm{OO}$ & $\mathrm{Y}=-350,2 x+3165$ & $-350,2$ тыс. грн. \\
\cline { 2 - 4 } & $\mathrm{OOO}$ & $\mathrm{Y}=-48,64 x+1135$ & $-48,64$ тыс. лей. \\
\hline
\end{tabular}

Источник: расчеты авторов по данным таблиц 1 и 2

Таблица 4

Расчетные показатели изменения финансово-экономических показателей деятельности AO «Cahulhan» (AO) и ООО «ПП Теклайн» (ООО) за 2014-2020 годы

\begin{tabular}{|c|c|c|c|c|c|}
\hline Показатели & Предприятие & $\begin{array}{c}\text { В среднем за } \\
2014-2020 \text { гг., } \\
\text { тыс. лей }\end{array}$ & $\begin{array}{c}\text { Средне- } \\
\text { годовые } \\
\text { отклонения, } \\
\text { тыс. лей }\end{array}$ & $\begin{array}{c}\text { Коэфрфи- } \\
\text { циент } \\
\text { вариации, \% }\end{array}$ & $\begin{array}{c}\text { Размах } \\
\text { вариации, } \\
\text { тыс. лей }\end{array}$ \\
\hline \multirow{2}{*}{$\begin{array}{c}\text { Доходы } \\
\text { от продаж }\end{array}$} & $\mathrm{AO}$ & 50381 & 3616 & 7,2 & 10023 \\
\hline & 000 & 19278 & 7454 & 38,7 & 20644 \\
\hline \multirow{2}{*}{$\begin{array}{c}\text { Себестоимость } \\
\text { продаж }\end{array}$} & $\mathrm{AO}$ & 37822 & 2302 & 6,1 & 6221 \\
\hline & 000 & 15226 & 8325 & 54,7 & 23035 \\
\hline \multirow{2}{*}{ Валовая прибыль } & $\mathrm{AO}$ & 12558 & 1395 & 11,1 & 3802 \\
\hline & 000 & 4052 & 1478 & 36,5 & 3370 \\
\hline \multirow{2}{*}{$\begin{array}{c}\text { Прибыль до } \\
\text { налогообложения }\end{array}$} & $\mathrm{AO}$ & 1193 & 545 & 45,7 & 1509 \\
\hline & 000 & 1765 & 909 & 51,5 & 2645 \\
\hline \multirow{2}{*}{ Чистая прибыль } & $\mathrm{AO}$ & 941 & 487 & 51,7 & 1295 \\
\hline & OOO & 1507 & 800 & 53,1 & 2302 \\
\hline
\end{tabular}

Источник: выполнено по данным таблиц 1 и 2

Таблица 5

Расчетные показатели изменения финансовых показателей деятельности AO «Cahulhan» и ООО «ПП Теклайн» за 2014-2020 годы

\begin{tabular}{|c|c|c|c|c|c|}
\hline \multirow{2}{*}{ Показатели } & \multirow{2}{*}{ Предприятие } & \multicolumn{2}{|c|}{ В среднем за } & \multicolumn{2}{|c|}{$\begin{array}{c}\text { Коэфрфициент вариации, } \\
\%\end{array}$} \\
\hline & & 2014-2016 гг. & 2018-2020 гг. & 2014-2016гг. & 2018-2020 гг. \\
\hline \multirow{2}{*}{$\begin{array}{l}\text { Доходы от } \\
\text { продаж }\end{array}$} & $\mathrm{AO}$ & 53735 & 46907 & 2,3 & 3,5 \\
\hline & 000 & 16914 & 22748 & 7,4 & 50,7 \\
\hline \multirow{2}{*}{ Себестоимость } & $\mathrm{AO}$ & 39873 & 35519 & 2,1 & 2,3 \\
\hline & 000 & 11586 & 20214 & 9,6 & 54,4 \\
\hline \multirow{2}{*}{ Валовая прибыль } & $\mathrm{AO}$ & 13862 & 11388 & 3,8 & 8,3 \\
\hline & 000 & 5328 & 2535 & 6,0 & 21,2 \\
\hline \multirow{2}{*}{$\begin{array}{c}\text { Прибыль до } \\
\text { налогообложения }\end{array}$} & $\mathrm{AO}$ & 1170 & 1223 & 48,2 & 61,7 \\
\hline & 000 & 2536 & 586 & 19,1 & 122,8 \\
\hline \multirow{2}{*}{ Чистая прибыль } & $\mathrm{AO}$ & 874 & 1034 & 59,2 & 62,6 \\
\hline & 000 & 2191 & 757 & 19,1 & 55,8 \\
\hline
\end{tabular}

Источник: выполнено по данным таблицы 1 
Расчет среднегодовых скользящих показателей чистой прибыли в AO «Cahulhan» и ООО «Теклайн» за 2014-2020 годы

\begin{tabular}{|c|c|c|c|c|}
\hline \multirow{2}{*}{ Год } & \multicolumn{2}{|c|}{ АО «Cahulhan» } & \multicolumn{2}{c|}{ ООО «ПП Теклайн» } \\
\cline { 2 - 5 } & за год & $\begin{array}{c}\text { в среднем за } \\
\text { последние 3 года }\end{array}$ & за год & $\begin{array}{c}\text { в среднем 3а } \\
\text { последние 3 года }\end{array}$ \\
\hline 2014 & 1414 & $\mathrm{x}$ & 2202 & $\mathrm{x}$ \\
\hline 2015 & 824 & $\mathrm{x}$ & 2605 & $\mathrm{x}$ \\
\hline 2016 & 383 & 874 & 1767 & 2191 \\
\hline 2017 & 862 & 690 & 1707 & 1434 \\
\hline 2018 & 1693 & 979 & 829 & 946 \\
\hline 2019 & 1012 & 1189 & 303 & 757 \\
\hline 2020 & 398 & 1034 & 1138 & \\
\hline
\end{tabular}

источник: расчеты авторов

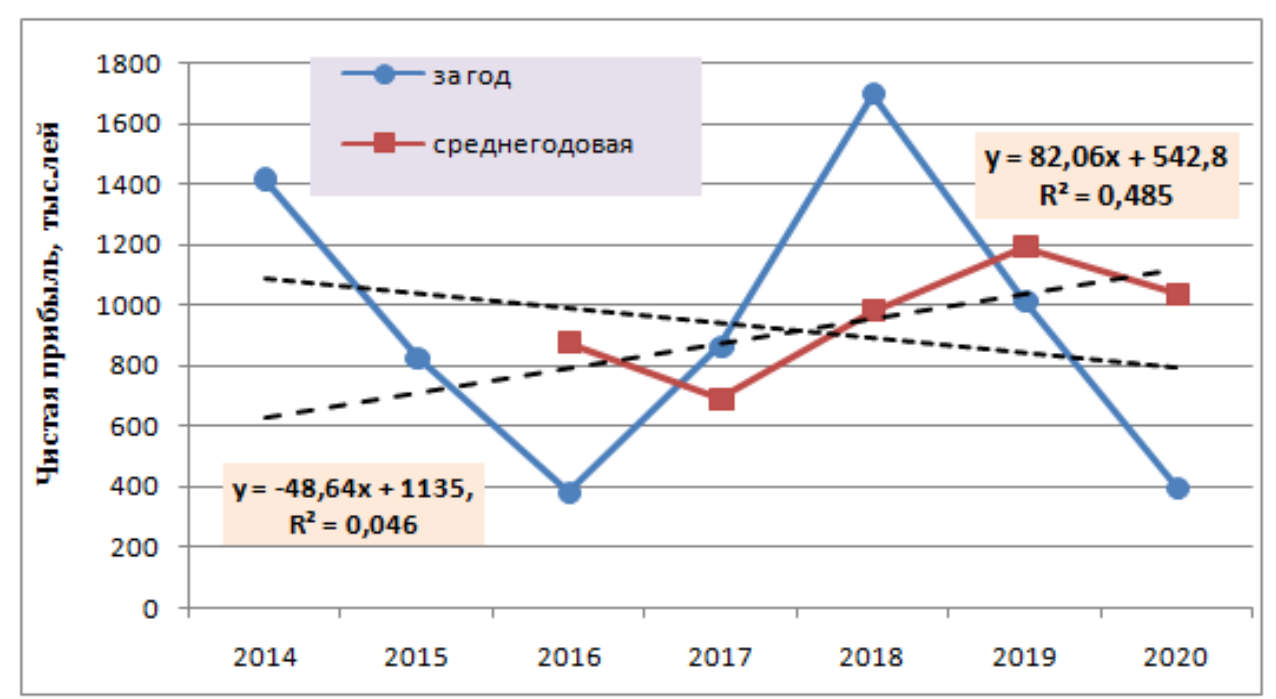

Рис. 3. Динамика чистой прибыли в AO «Cahulhan» за 2014-2020 годы (годовой и среднегодовой варианты)

Источник: выполнено авторами по данным таблицы 6

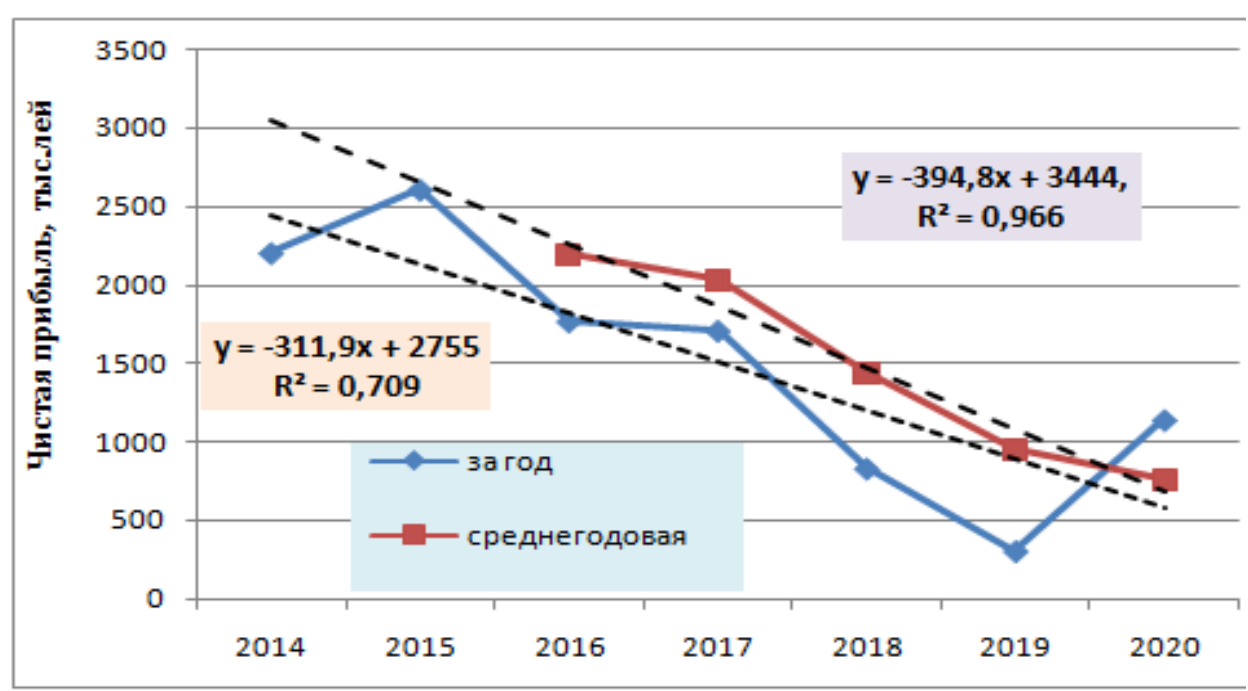

Рис. 4. Динамика чистой прибыли в ООО «ПП Теклайн» за 2014-2020 годы (годовой и среднегодовой варианты)

Источник: выполнено авторами по данным таблицы 6 
ООО «ПП Теклайн» - с 0,709 до 0,966 или почти в 1,4 раза.

Уровень стабильности фринансово-экономических показателей является мерилом результативности и рискованности маркетинговой деятельности предприятия. Именно этим объясняется важность оценки данных показателей при определении уровня экономической безопасности предприятия. Следовательно, перерабатывающим предприятиям, поставляющим продукцию на экспорт и прежде всего использующих в качестве сырья продукцию агропредприятий, расположенных в зонах неустойчивого земледелия, целесообразно выполнять расчеты среднегодовых скользящих значений доходов от реализации, валовой и чистой прибыли и на их основе проводить анализы результативности маркетинговой деятельности предприятия [9, с. 102].

Выводы. В ходе исследования были использованы приемы экономико-статистического метода, а также приемы сравнительного анализа, среднегодовых скользящих показателей и грасрический метод. Они позволили в полной мере достичь цели исследования: показать особенности анализа результативных показателей маркетинговой деятельности перерабатывающих предприятий в условиях нестабильной внешней среды. Особой актуальностью отличается необходимость выполнения всестороннего анализа фринансовых показателей в динамике по предложенной выше методике для предприятий, которые поставляют на экспорт продукцию агропромышленного комплекса и являются зависимыми от условий внешней среды и неустойчивого земледелия. Она отличается простотой и доступностью как для студентов, так и для специалистов предприятий. Использование приемов расчета среднегодовых скользящих значений доходов от реализации, валовой и чистой прибыли в сочетании с графрическим методом позволит предприятиям агропромышленного комплекса, функционирующим в сорере внешней торговли, повысить объективность анализа результативности маркетинговой деятельности и сорормировать банк трендовых моделей динамики как важной составляющей маркетинговой инорормационной системы. Дальнейшие исследования будут направлены на обоснование методики анализа эфффективности затрат на маркетинг и маркетинговые коммуникации в сорере внешнеторговой деятельности перерабатывающих предприятий.

\section{СПИСОК ИСПОЛЬЗОВАННЫХ ИСТОЧНИКОВ:}

1. Гайдукович Д.С. Характеристика інструментів маркетингового аналізу в сфрері банківських послуг. Вісник соціально-економічних досліджень. 2011. Випуск 3(43). 50. С. 50-55.

2. Штефранич Д., Братко О., Дячун О., Лагоцька Н., Окрепкий Р. Маркетинговий аналіз / За ред. доктора економічних наук, професора Д.А. Штефанича. Тернопіль : Економічна думка, 2011. 267 с.

3. Дейнега О.В. Маркетинговий аналіз як інструмент задоволення інфрормаційних потреб ринково орієнтованого підприємства. Глобальні та національні проблеми економіки. 2017. Випуск 18. С. 201-206. URL: http://global-national.in.ua/archive/18-2017/39.pdf (дата звернення: 20.09.2021).

4. Морохова В.О., Бойко В.О., Борзаковська Л.В. Методичні положення комплексного маркетингового аналізу та прогнозування розвитку ринку торгівельного обладнання. Науковий вісник Полісся. 2018. № 2(1(13). C. 191-198. URL: http://nvp.stu.cn.ua/article/view/139860 (дата звернення: 20.09.2021).

5. Стрий Л.А. Маркетинговое управление на рубеже XXI ст.: системное исследование. Одесса : АстроПринт, 2000. 304 с.

6. Штучка Т.В. Методичні підходи до оцінки маркетингової діяльності підприємств агропродовольчого сектору. Економічний аналіз. 2014. Том 18. № 3. С. 96-102.

7. Пармакли Д.М., Тодорич Л.П., Дудогло Т.Д., Кураксина С.С., Яниогло А.И. Продуктивность земли в сельском хозяйстве. Монограсрия: под ред. Д.М. Пармакли; Комрат. Гос.ун-т, Н-и. центр «Прогресс». Комрат, 2017 (Tipogr. "Centrografic"). 242 c.

8. Пармакли Д.М., Тодорич Л.П., Дудогло.Т.Д., Яниогло А.И. Эфффективность землепользования: теория, методика, практика : монограсрия. Комрат : Б. и., 2015 (Tipogr. "Centrografic"). 274 с.

9. Пармакли Д.М. Эффрективность использования земли в сельском хозяйстве АТО Гагаузия: теория и практика : монографрия. Комрат : Научно-исследовательский Центр Гагаузии им. М.В. Маруневич, 2019. 278 с.

\section{REFERENCES:}

1. Ghajdukovych D.S. (2011) Kharakterystyka instrumentiv marketynghovogho analizu v sferi bankivsjkykh poslugh. Visnyk socialjno-ekonomichnykh doslidzhenj, 3(43), 50, 50-55. (in Ukrainian) 
2. Shtefanych D., Bratko O., Djachun O., Laghocjka N., Okrepkyj R. (2011) Marketynghovyj analiz / Za red. doktora ekonomichnykh nauk, profesora D.A. Shtefanycha. Ternopilj: Ekonomichna dumka, 267 p. (in Ukrainian)

3. Dejnegha O.V. (2017) Marketynghovyj analiz jak instrument zadovolennja informacijnykh potreb rynkovo orijentovanogho pidpryjemstva. Ghlobaljni ta nacionaljni problemy ekonomiky, 18, 201-206. Available at: http://global-national.in.ua/archive/18-2017/39.pdf (accessed 20 September 2021).

4. Morokhova V.O., Bojko V.O., Borzakovsjka L.V. (2018) Metodychni polozhennja kompleksnogho marketynghovogho analizu ta proghnozuvannja rozvytku rynku torghiveljnogho obladnannja. Naukovyj visnyk Polissja, 2(1(13), 191-198. Available at: http://nvp.stu.cn.ua/article/view/139860 (accessed 20 September 2021).

5. Strij L.A. (2000) Marketingovoe upravlenie na rubezhe HHI st.: sistemnoe issledovanie Odessa: AstroPrint, 304 p. (in Russian)

6. Shtuchka T.V. (2014) Metodychni pidkhody do ocinky marketynghovoji dijaljnosti pidpryjemstv aghroprodovoljchogho sektoru. Ekonomichnyj analiz, 18(3), 96-102. (in Ukrainian)

7. Parmakli D.M., Todorich L.P., Dudoglo T.D., Kuraksina S.S., Janioglo A.I. (2017) Produktivnost' zemli v sel'skom hozjajstve. Monografija: pod red. D.M. Parmakli; Komrat. Gos.un-t, N-i. centr «Progress». Komrat, (Tipogr. "Centrografic"), 242 p. (in Russian)

8. Parmakli D.M., Todorich L.P., Dudoglo.T.D., Janioglo A.I. (2015) Jeffektivnost' zemlepol'zovanija: teorija, metodika, praktika: monografija. Komrat: B. i., (Tipogr. "Centrografic"), 274 s. (in Russian)

9. Parmakli D.M. (2019) Jeffektivnost' ispol'zovanija zemli v sel'skom hozjajstve ATO Gagauzija: teorija i praktika (monografija). Komrat, Nauchno-issledovatel'skij Centr Gagauzii im. M.V. Marunevich, 278 p. (in Russian) 